\title{
Preweanling handling influences open-field behavior, but not negative contrast or sucrose neophobia
}

\author{
ANNE B. MEINRATH and CHARLES F. FLAHERTY \\ Rutgers University, New Brunswick, New Jersey
}

\begin{abstract}
Handling of preweanlings (Days 2-15) had substantial effects on the open-field behavior of rats when tested as adults. In general, handled rats reared more, ambulated more, and defecated less than nonhandled rats. However, the handling manipulation had no effect on the degree of negative contrast that occurred when rats were shifted from 32\% to $4 \%$ sucrose. Experiments 2 and 3 showed that preweaning handling did not influence sucrose neophobia in two different test situations. These data, in conjunction with those of other studies, suggest that preweaning handling may have powerful but limited effects on adult behavior, and that these effects are probably not best characterized in terms of global concepts such as emotionality.
\end{abstract}

Rats handled before weaning are different both behaviorally and physiologically from nonhandled rats. For example, handled animals have been reported to show superior avoidance learning and to be less emotionally reactive as adults, as measured by differences in open-field behavior and plasma corticosterone responses (e.g., Levine, 1956; Levine, Haltmeyer, Karas, \& Denenberg, 1967). Handled rats have also been found to investigate novel stimuli or novel environments more than nonhandled rats (e.g., Denenberg \& Grota, 1964; Haltmeyer, Denenberg, \& Zarrow, 1967) and to show less elevation of plasma corticosterone in response to novel stimuli than nonhandled animals (Ader, 1970; Hess, Denenberg, Zarrow, \& Pfeifer, 1969). More recently, it has been demonstrated that rats handled on Days 2-15 of the preweaning period licked more of a novel $30 \%$ sucrose solution than did nonhandled animals when the solution was presented in the home cage when the rats were 90-120 days of age. Furthermore, the handled animals showed less of a conditioned aversion when a novel milk solution was paired with a toxin, and more rapid recovery to pretoxicosis drinking levels, than did nonhandled animals (Weinberg, Smotherman, \& Levine, 1978).

These varied effects of the early handling procedure would seem to make the paradigm particularly relevant to interpretations of the negative contrast effect that occurs when reward quantity or quality is reduced. That is, negative contrast has often been explained in terms of a decrement in behavior produced by the novel stimulus of a new reward (e.g., Capaldi \& Lynch, 1967), in terms

This research was submitted in partial fulfillment of the requirements for the degree of Doctor of Philosophy at Rutgers University by the first author. The research was supported by a grant from the Charles and Johanna Busch Fund and by Grant MH-40489 from the National Institute of Mental Health. The authors' mailing address is: Department of Psychology, Busch Campus, Rutgers University, New Brunswick, NJ 08903. of an emotional response elicited by the reduced reward (e.g., Crespi, 1942, 1944), or in terms of both neophobic and emotional responses (Flaherty, 1982).

Of particular relevance to the present paper is the contrast in consummatory behavior that occurs when sucrose concentration is decreased. Rats allowed access to $32 \%$ sucrose 5 min per day for 10 days and then shifted to a 4\% sucrose solution consume substantially less of the $4 \%$ sucrose than do rats that have experienced only the $4 \%$ sucrose solution. The animals typically recover from this negative contrast effect over a 4-day postshift period (e.g. Flaherty, Lombardi, Wrightson, \& Deptula, 1980).

The involvement of an emotional response in this contrast effect is suggested by several items of evidence. For example, contrast is reduced or eliminated by lesions of the amygdala (Becker, Jarvis, Wagner, \& Flaherty, 1984), but not by lesions of the septum (Flaherty, Powell, \& Hamilton, 1979). Contrast is also alleviated by drugs that function as anxiolytics in humans. Thus, the benzodiazepine tranquilizers chlordiazepoxide and midazolam eliminate contrast (Becker, 1984; Flaherty et al., 1980), and ethanol reliably reduces contrast but does not eliminate it (Becker \& Flaherty, 1982). In addition, ethanol and chlordiazepoxide have additive effects in reducing contrast (Becker \& Flaherty, 1983). Finally, it has been shown that the occurrence of contrast is accompanied by an elevation in corticosterone (Flaherty, Becker, \& Pohorecky, 1985).

Given the evidence that early handling reduces emotionality and that an emotional response may be a component of contrast, there is reason to hypothesize that rats exposed to the early handling treatment should show less of a contrast effect when tested as adults than nonhandled control animals. However, there is also reason to raise such a hypothesis guardedly, since Sias and Brush (1984) reported no effects of early handling manipulation on the avoidance performance of selectively bred strains 
that were either high or low avoiders. Also, Daly and Rosenberg (1973) reported no effects of early handling on runway contrast, a procedure that is similar in many ways to contrast in consummatory behavior but is also different in some respects (Flaherty, 1982; Flaherty \& Caprio, 1976). In addition, Fagen and Rycek (1980) have reported that handling of preweanlings has no effect on simultaneous contrast obtained in the consumption of sucrose solutions. However, other evidence indicates that such simultaneous contrast reflects the operation of sensory, rather than emotional, processes, and thus might not be expected to be influenced by early handling (Flaherty, 1982; Flaherty, Lombardi, Kapust, \& D'Amato, 1977; Flaherty \& Sepanak, 1978).

The present experiments are concerned with the effect of preweaning handling on open-field behavior and on the successive negative contrast effect in consummatory behavior that occurs when rats are shifted from $32 \%$ to $4 \%$ sucrose.

\section{EXPERTMENT 1}

In this experiment we investigated the effects of preweaning handling on the occurrence of negative contrast when the animals were tested as adults. All animals (handled and nonhandled) were tested in a negative consummatory contrast paradigm and in the open field (as a check on the effectiveness of the handling manipulation). Half of the animals were tested in the open field prior to contrast testing; the remainder were tested in the opposite order.

\section{Method}

\section{Subjects}

The subjects were 80 male albino rats obtained from 18 litters ( 9 handled and 9 nonhandled) bred in our laboratory from SpragueDawley males and females (multiparous) purchased from Charles River Breeding Laboratories. The animals were maintained on a 14-h/10-h light/dark cycle throughout the experiment.

\section{Apparatus}

The handling apparatus consisted of a cardboard box divided into eight separate compartments measuring $17.2 \times 8.8 \times 17.2 \mathrm{~cm}$.

The apparatus for contrast testing consisted of six identical steel hanging cages measuring $24.5 \times 17.5 \times 18 \mathrm{~cm}$. The six cages were placed along a bench in individual 42-cm compartments bounded by 7-mm-thick Masonite partitions measuring $58 \times 58 \mathrm{~cm}$. Each cage was mounted on 2-cm blocks and was covered by a hinged wooden top. Each cage had an $8.5 \times 8.5 \mathrm{~cm}$ Plexiglas plate with a 1.5-cm-diam hole drilled in the center on the front of the cage. A graduated cylinder was mounted on the Masonite partition, so that the metal drinking spout of the cylinder was centered in the $1.5-\mathrm{cm}$-diam hole, flush with the outside of the Plexiglas plate. A contact relay circuit was used to measure the licking response. A Data General Nova/2 computer in an adjacent room recorded the number of licks per $10 \mathrm{sec}$ and per $1 \mathrm{~min}$ for $5 \mathrm{~min}$, beginning with the first lick.

The open field was constructed of $1.27-\mathrm{cm}$ plywood and measured $121.92 \times 129.92 \times 30.48 \mathrm{~cm}$. The surfaces were painted flat black except for thin white lines dividing the floor into $10.16-\mathrm{cm}$ squares. Illumination was provided by a $40-\mathrm{W}$ bulb centered $2.4 \mathrm{~m}$ above the field. White noise $(80 \mathrm{~dB})$ was present in both testing rooms.

\section{Procedure}

Breeding and handling. About 1 week before giving birth, the gravid females were housed individually in $47.2 \times 25.2 \times 15.2 \mathrm{~cm}$ plastic breeding cages or $41.3 \times 24.6 \times 21.5 \mathrm{~cm}$ metal breeding cages with wood shavings as bedding. At birth (Day 1), the litters were culled to approximately 8 pups each, leaving as many male pups as possible, and were assigned to either the handled $(\mathrm{H})$ or the nonhandled (NH) condition. The mean number of pups per litter after culling was 7.7 for both $\mathbf{H}$ and $\mathbf{N H}$ litters. Assignment of litters to condition was random with the provision that the number of litters in each type of breeding cage be equal for the two conditions.

After culling, the NH litters were left completely undisturbed until weaning. The handling manipulation took place on Days $2-15$. On each of these days, the dams of the $H$ litters were removed and placed in bolding cages. The pups were then removed one by one and placed into the individual cardboard compartments for $3 \mathrm{~min}$. The pups and dams were then returned to the breeding cages. From Day 16 until weaning, the $H$ litters were undisturbed.

Handling and maintenance procedures were carried out daily between 9:30 and 11:30 a.m. The litters and all gravid females were kept in a separate colony room entered only by the experimenter during the prescribed time.

On Day 22, all litters were weaned. The pups were weighed and housed in pairs (with same-sex littermates) in hanging metal cages. The animals were rehoused individually in similar cages at approximately 50-60 days of age and were maintained from weaning until testing on food (Purina Lab Chow) and water ad lib.

Order of testing. Forty subjects, one half of the $\mathrm{H}$ and one half of the NH animals, were run initially in the contrast paradigm (CON) followed by open-field (OF) testing. The remaining 40 animals were first tested in the OF and then in the CON paradigm. The timing of the testing was arranged such that all animals began the CON testing at approximately the same age and were at least $\mathbf{7 0}$ days of age. Because of the staggered births of the litters, it was necessary to run each of the two order conditions (CON-OF and OF$\mathrm{CON}$ ) in two passes. In the CON-OF condition, 28 animals (16 H and $12 \mathrm{NH}$ ) were run in the first pass and 12 animals (4 H and $8 \mathrm{NH}$ ) were run in the second pass. The second pass started 23 days after the first pass began. The animals in the CON-OF order condition were a mean of 78.6 days old when contrast testing began (range $=70-86$ days; mean age $=80$ days for the $H$ animals and 77.2 days for the NH animals).

In the OF-CON condition, 8 animals were run in the first pass (4 $\mathrm{H}$ and $4 \mathrm{NH}$ ) and 28 animals (14 H and $14 \mathrm{NH}$ ) were run in the second pass, which began 24 days after the start of the first pass. The animals in the OF-CON condition were a mean of 76.1 days of age when contrast testing began (range $=71-86$ days; mean age $=77.1$ days for the $\mathrm{H}$ animals and 75.1 days for the $\mathrm{NH}$ animals).

Contrast and open-field testing. Six days prior to the start of contrast testing, animals in the CON-OF condition were deprived to $80 \%$ (mean $=343.95 \mathrm{~g}$ for the $\mathrm{H}$ animals and $340.66 \mathrm{~g}$ for the NH animals) of their free-feeding body weights and were maintained at that level by limits on their daily food ration. The animals were fed their rations $30 \mathrm{~min}$ after the test sessions. Water was freely available in the home cages at all times.

Assignment to contrast testing groups took place as follows: Half of the male rats from each $H$ and each $N H$ litter were randomly assigned to the shift condition and the other half were assigned to the control condition, forming four groups of 10 (shift-H, control- 
H, shift-NH, and control-NH). Animals in the shift condition received a $32 \%$ sucrose solution during the preshift phase of the experiment and $4 \%$ sucrose solution during the postshift phase. Animals in the control condition received a $4 \%$ solution in both phases.

On each test day the animals were weighed and placed in separate compartments in a wooden carrying cage for transport to the test apparatus. Beginning on Day 1 of testing, each animal was placed into a test chamber with the tube containing the appropriate sucrose solution (32\% or $4 \%$ ) in place. Handling condition was counterbalanced across test chambers such that an equal number of $H$ and NH animals were run in each chamber. All control animals were run before the shift animals. Licks per $10 \mathrm{sec}$ and per $1 \mathrm{~min}$ were recorded for $5 \mathrm{~min}$, beginning with the animals' first lick. At the end of the 5-min period, the animals were removed and returned to their home cages. Preshift training continued in this manner for 10 days. On Test Days 11-14, the postshift phase, the procedure remained the same except that all animals received a $4 \%$ sucrose solution.

The sucrose solutions were prepared by weight [solute/(solute + solvent)] from commercial-grade cane sugar and tap water. New solutions were prepared every 2 days. Every 3 days the test chambers were cleaned and the paper under the chambers was changed.

Following contrast testing on Test Day 14, the animals were maintained on food and water ad lib for 4 days before testing began in the open field. On Test Days 19-21, the animals were weighed and placed in carrying cages for transport to the open-field apparatus. Each animal was placed in the center of the open field and left for $3 \mathrm{~min}$. The experimenter, who was seated at one end of the apparatus (about $2 \mathrm{ft}$ away), recorded the number of squares entered (defined by placement of both front paws in a square), the number of rears, and the time in motion for the 3-min period. After the animal was removed, the number of defecations was recorded and the floor was wiped clean with a damp sponge. The animals were then returned to their home cages.

In the OF-CON condition, the animals were initially tested in the open field for 3 days (Test Days 1-3) in the manner described above. For the next 6 days, the animals were reduced to $80 \%$ of their free-feeding body weights (mean $=346.2 \mathrm{~g}$ for the $\mathrm{H}$ animals and $321.5 \mathrm{~g}$ for the $\mathrm{NH}$ animals) and were maintained at that level during contrast testing. Contrast testing began on Test Day 10 and was conducted in the same manner as above. Assignment to shift or control condition was similar, with one half of each $H$ litter and one half of each NH litter randomly assigned to each group.

To ascertain the reliability of the open-field measures made by the experimenter, two additional observers monitored some of the animals and recorded the number of squares entered, number of rears, and number of defecations on 1 of the test days in the CON-OF condition and on all 3 test days in the OF-CON condition. Both observers were naive as to the status of the animals ( $\mathrm{H}$ or $\mathrm{NH}$ ). These observers monitored a total of 46 animals (23 H and $23 \mathrm{NH}$ animals).

\section{Results}

\section{Open-Field Behavior}

The number of squares entered, number of rears, and time spent in motion during the 3-min test periods were analyzed using analysis of variance procedures. Handling condition (H or NH), concentration (shift or control), order (CON-OF or OF-CON), and litter were betweensubjects factors; handling, concentration, and order were crossed, and litter was nested in handling and order. Day of testing was a within-subjects factor.

Results obtained with all three dependent variables were similar. As can be seen in Figure 1, a substantial effect of the handling manipulation was found in each facet of open-field behavior: The $H$ animals entered more squares $[F(1,14)=21.93, p<.001]$, reared more $[F(1,14)=$ $5.24, p<.05]$, and spent more time in motion $[F(1,14)$ $=22.67, p<.001]$ than did the NH animals. The number of squares entered by the $H$ animals increased from Day 1 to Day 3 of testing, but the NH animals tended to maintain the same level of activity on all days [handling $X$ day interaction, $F(2,28)=3.44, p<.05, L S D=$ $.05]$. The number of rears decreased significantly from Day 1 to Day 2 and remained unchanged on Day 3 $[F(2,28)=4.13, p<.05, L S D=.05]$, as did the time spent in motion $[F(2,28)=4.85, p<.05, L S D=.05]$. There were no handling $x$ day interactions in the latter two variables.

There were several differences in the two orders of testing. The effect of the handling manipulation was not as substantive when the open-field testing occurred after the contrast testing. This effect was due primarily to differences in the NH-control group in the two orders. In general, the experience of contrast testing prior to openfield testing increased activity of the nonhandled control animals [order $\times$ concentration $\times$ handling, $F(1,14)=$ $4.84, p<.05, L S D=.05$; order $\times$ concentration $\times$ handling $\times$ day, $F(2,88)=3.84, p<.05, L S D=.05]$. In addition, the animals reared more in the CON-OF order than in the OF-CON order $[F(1,14)=9.90, p<.01]$.

There were litter differences in all three measures [squares, $F(14,44)=1.94, p<.05$; rears, $F(14,44)=$ $3.66, p<.001$; time, $F(14,44)=2.29, p<.05]$ and several interactions of litter with day of testing, indicating that different litters performed in different ways over days.

Because a relatively small number of animals defecated during open-field testing, it was felt that an analysis of variance on number of defecations would be inappropriate. Instead, the chi-square statistic was used to determine differences in the numbers of $\mathrm{H}$ and $\mathrm{NH}$ animals defecating on each test day. Although more NH animals defecated on all 3 days, this difference reached significance only on Day 2 [Day $1, x^{2}(1)=0.85, p>.05$; Day $2, \chi^{2}(1)$ $=5.23, p<.05$; Day 3, $\left.x^{2}(1)=1.83, p>.05\right]$.

Pearson product-moment correlations (based on the individual scores of all animals) were calculated between all open-field variables, including number of defecations, for each day of testing. It was found that squares, rears, and time in motion were positively correlated on all test days ( 35 of 36 correlations were significant at the .05 or .01 level, and all were positive). In general, correlations between different measures on the same test day and between different days of the same measure tended to be higher. The correlations between number of defecations and the other measures were predominately negative (with the exception of the positive correlations between defecations on different days), although only 8 of the 30 correlations were significant. Number of defecations did not seem to correlate more or less strongly with any other open-field measure. 


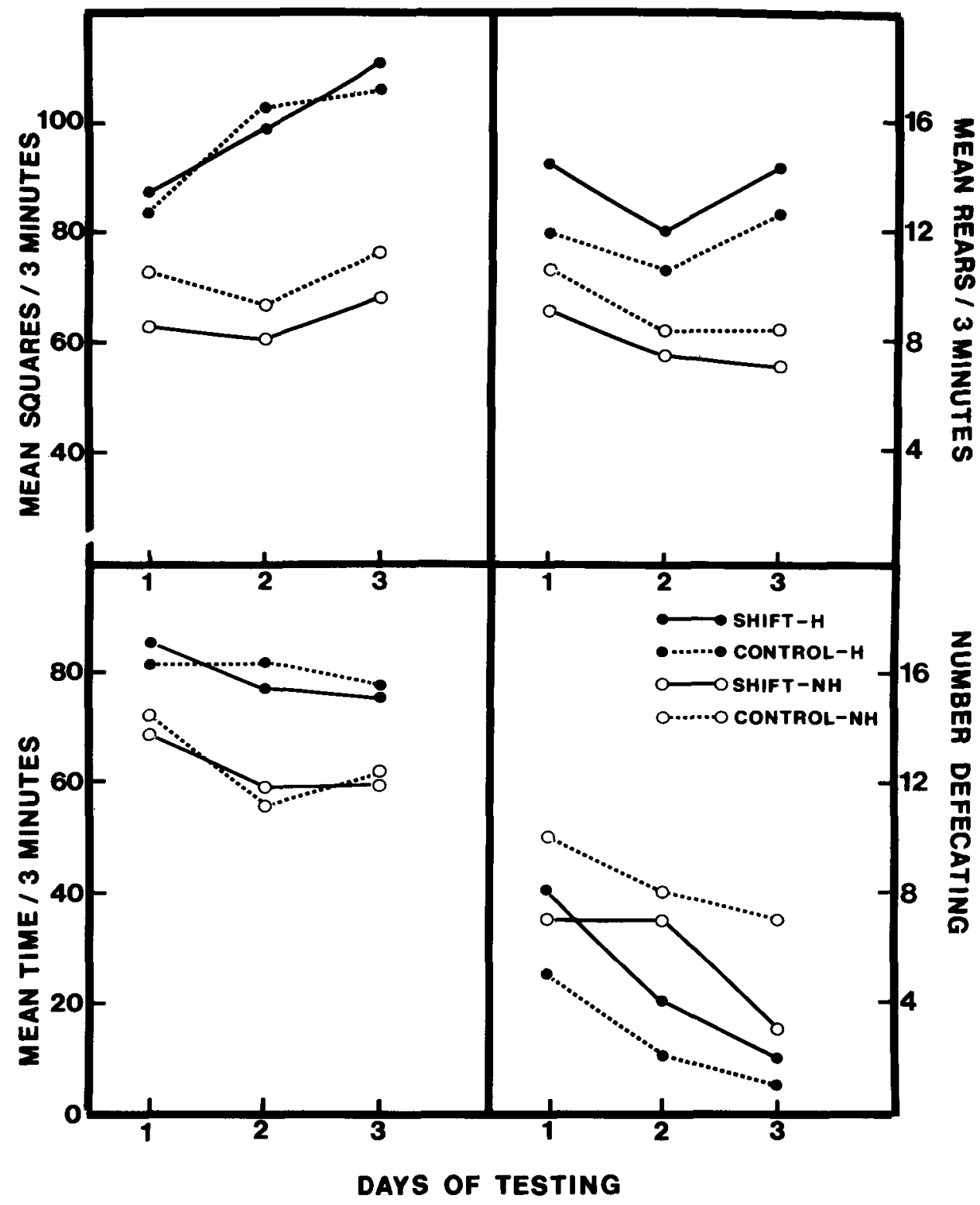

Figure 1. Open-field data (squares traversed, time in motion, rears, and defecations) in handled (H) and nonhandled (NH) rats.

Finally, to ensure the reliability of the open-field observations, interrater correlations were calculated between the ratings of the experimenter and the two additional observers. All interrater correlations were at or above .96, and the means of the ratings were almost identical.

\section{Contrast Testing}

Analysis of variance procedures identical to those used with the open-field data were used to analyze the contrast data (number of licks per 5-min access period). The data of the preshift (Days 6-10 only) and the postshift phases were considered separately.

The mean number of licks during the daily sessions for each group is shown in Figure 2. During Days 6-10, the
$32 \%$ animals licked more than did the $4 \%$ animals $[F(4,56)=20.45, p<.001, L S D=.01]$. Although the $\mathrm{H}$ animals licked numerically more than did the NH animals, this difference was not statistically reliable $[F(1,14)=2.71, p>.05]$. The litters were different in their licking levels $[F(14,44)=1.97, p<.05]$, but litter did not interact with any other variable. None of the potential interactions with the handling manipulation approached statistical reliability.

On Days 11-14 (the postshift phase), the shift animals fell substantially below the level of the control animals in number of licks $[F(1,14)=131.54, p<.0001]$. Recovery from this negative contrast effect occurred over the 4 postshift days $[F(3,42)=47.58, p<.0001, L S D$ 


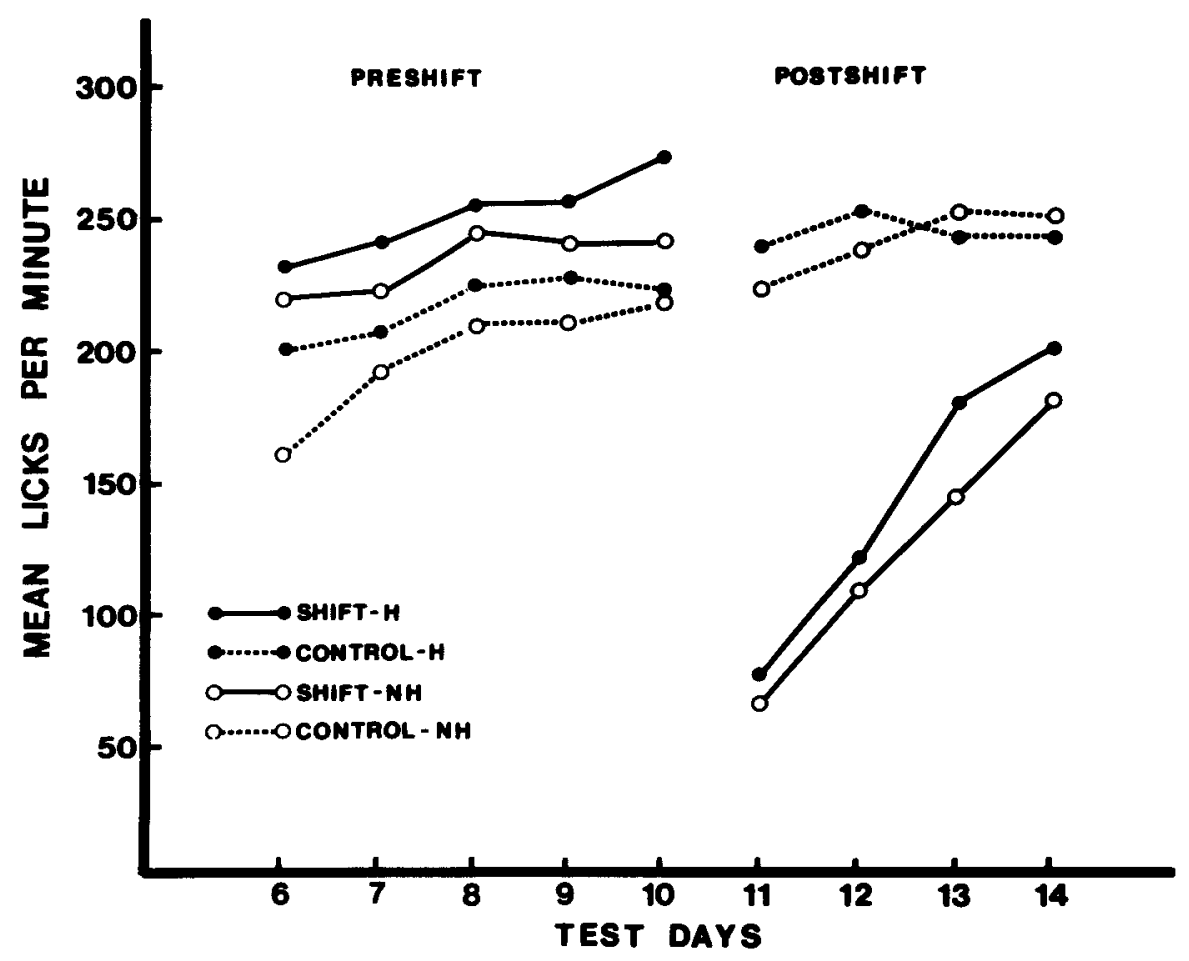

Fizure 2. Mean licks over last 5 predhin days (6-10) and over 4 pocthin days (11-14) in shifted (32-4) and unshifted (4-4) rats as a function of handing condition.

$=.01]$. There was a tendency for the $\mathrm{H}$ animals to lick more than the NH animals in the postshift period, a tendency that was reliable on Day 13 only $[F(3,42)=3.62$, $p<.05, L S D=05]$. However, this difference may largely reflect a numerical difference that existed before shifting rather than a faster recovery from contrast by the $\mathrm{H}$ animals.

The litters were different in their licking rates $[F(14,44)$ $=4.68, p<.001]$, but litter did not interact with any other variable.

To further explicate the course of negative contrast and recovery, the licking data were examined on a minuteby-minute basis. Figure 3 shows the mean licks per minute for each 5-min daily postshift session for the $\mathbf{H}-$ and NH-shift groups. Both groups demonstrated a decrement in licking in the first minute of exposure to the $4 \%$ solution. Licking continued to decline until Minute 5 of the first postshift day, when it increased slightly in the H-shift group. However, the H-shift group was not reliably different from the NH-shift group at this point $[t(18)$ $=1.10, p>.05]$. On each successive day of exposure, the licking levels increased, particularly on Days 12 and 13. The recovery taking place between days was greater than recovery within days.

Correlations were computed between lick frequencies on Days 10-14 and all four measures of open-field behavior on each of the 3 open-field test days. Of 60 correlations, only 1 reached reliability. Thus, there appeared to be no relationship between open-field behavior and consummatory behavior.

\section{Body Weights}

The body weights of the animals at weaning and as adults at the beginning of contrast testing were examined by $t$ test. There were no differences between the $H$ and NH litters at weaning [mean $=67.15 \mathrm{~g}$ for the $\mathrm{H}$ animals and $67.13 \mathrm{~g}$ for the NH animals; $t(28)=.006, p>.05]$ or at the beginning of the contrast testing [mean = $344.95 \mathrm{~g}$ for the $\mathrm{H}$ animals and $331.1 \mathrm{~g}$ for the $\mathrm{NH}$ animals; $t(78)=1.85, p>.05]$.

\section{Discussion}

In agreement with previous findings (e.g., Levine et al., 1967; Whimbey \& Denenberg, 1967), the handling manipulation was found to be effective in the modification of behavior in the open field. The $\mathrm{H}$ animals ambulated more, reared more, and defecated less than did the NH animals, a profile of behavior considered to represent less emotional animals.

There were, however, differential effects of order of testing. The animals in the CON-OF order condition reared more and defecated less than did the OF-CON animals. Furthermore, the differences in ambulation due to handling were not as substantive in the animals that had experienced contrast testing prior to the assessment of open-field behavior. This result appeared to be due primarily to the behavior of the NH-control group. In the OF-CON order, ambulation levels of the NH-control group were equivalent to those of the NH-shift group and well below those of the $\mathrm{H}$ groups. But the $\mathrm{NH}$ controls ambulated more in the CON-OF order than in the OF- 


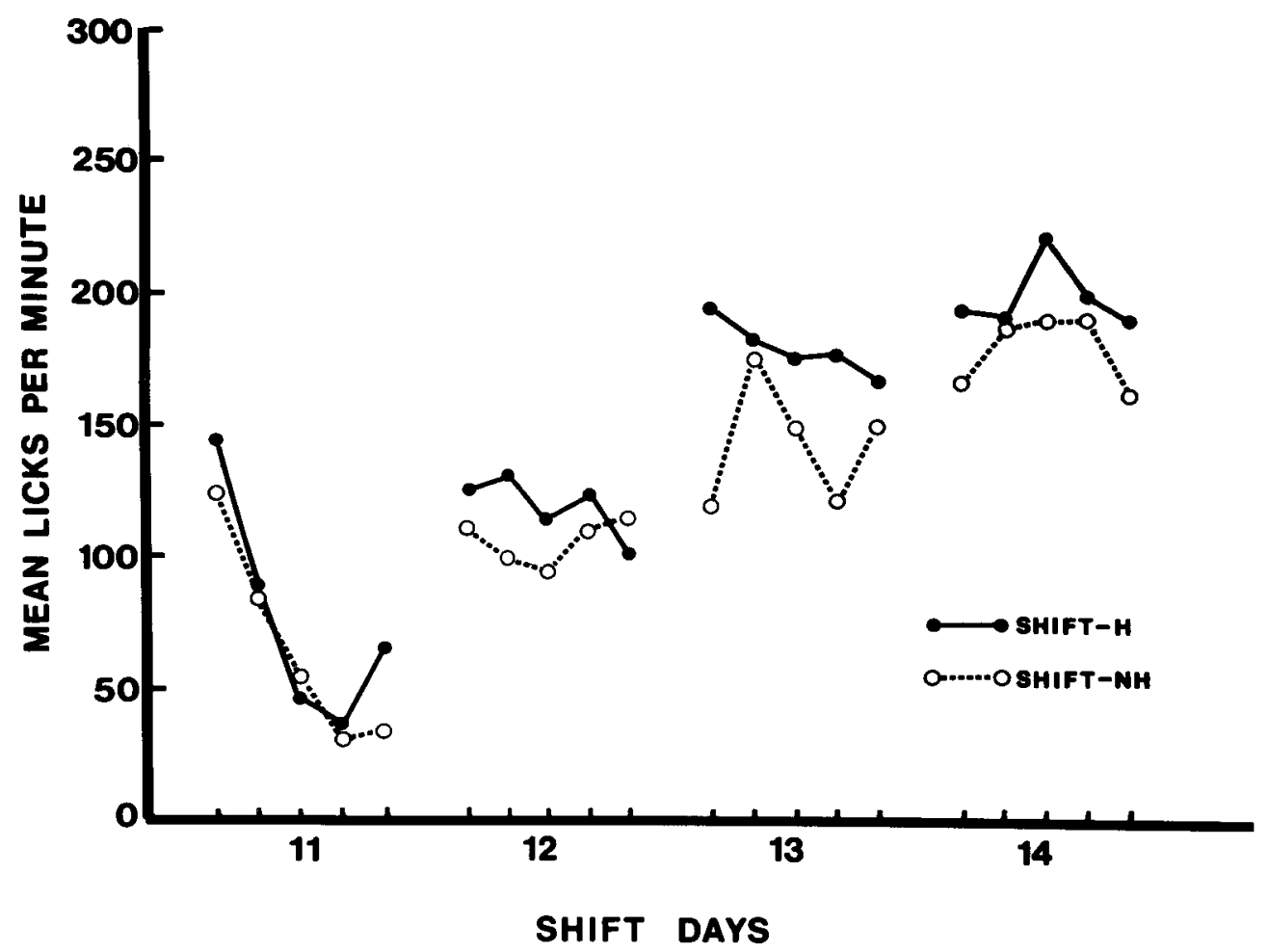

Figure 3. Minute-by-minute recovery from contrast in handled and nonhandled rats.

CON order and were different from the $\mathbf{H}$ animals only on the third test day.

Two previous findings suggest an explanation for these order differences. Walsh and Cummins (1976) proposed that behavior in the open field is determined by multiple factors, including stimulation due to removal from the home-cage environment and transfer to the test area, in addition to exposure to the novel test environment. Abel (1971) found that animals that were familiarized with transport procedures prior to open-field testing ambulated more at the start of open-field trials. Additionally, Cooper and Crummy (1978) reported that their adult rats handled by the experimenter for 20 days prior to testing were less emotional in a food-preference-test environment than were the animals not handled until the beginning of testing.

In the present experiment, the CON-OF animals experienced the same transport procedures during contrast testing and in open-field testing (i.e., contact with and handling by the experimenter, weighing, placement in and removal from the carrying cage). Habituation to these procedures may have resulted in the animals' being less emotional at the time of placement in the open field, and therefore in the occurrence of higher activity levels in this order condition. The experimenter observed that the OFCON animals defecated frequently in the carrying cage during transport to the open field, whereas the CON-OF animals rarely defecated during this time. Thus, the increased rearing and lower defecation levels in the CONOF order may be explained by prior experience with the transport procedures.
Squares traversed, rears, and time in motion were found to be positively correlated on all test days. Ivinskis (1966, 1968) and others (e.g., Price \& Huck, 1976; Ray \& Hockhauser, 1969) found positive correlations of a magnitude similar to those reported between movement into squares and rears (even though those behaviors are mutually exclusive) and considered rearing and ambulation to be measures of a single behavioral dimension.

In summary, the handling manipulation was effective in producing behavioral differences in animals consistent with those obtained in previous research. These differences in open-field behavior suggested that the $\mathrm{H}$ animals were less emotional than the NH animals. However, a substantial and equivalent negative contrast effect occurred in $\mathrm{H}$ and NH animals. The failure of early handling to influence successive negative contrast in consummatory behavior is consistent with the findings of previous studies in which the handling procedure failed to influence simultaneous contrast obtained in sucrose consumption (Fagen \& Rycek, 1980) and successive negative contrast obtained in runway behavior following a decrease in the quantity of reward (Daly \& Rosenberg, 1973). The lack of effect of early handling in these three different contrast paradigms suggests quite strongly that incentive relativity processes are not subject to influence by the early handling manipulation.

These results indicate a conflict between the substantial evidence cited in the introduction and in earlier papers (e.g., Daly, 1974; Flaherty, 1982), which indicates that successive negative contrast involves an emotional 
response and possibly neophobia, and the evidence that early handling reduces emotionality and neophobia. A possible resolution of this conflict is the suggestion of Daly and Rosenberg (1973) that early handling may influence fear-related emotionality but not the frustration-related emotionality that is presumably involved in contrast. This suggestion is supported by the current results. Furthermore, the recent failure of the early handling treatment to influence avoidance responding in genetically selected lines of high and low avoiders (Sias \& Brush, 1984) indicates that the effects of the early handling procedure are quite specific and do not influence presumed global processes such as emotionality and neophobia.

\section{EXPERIMENT 2}

Experiment 1 demonstrated that handling of preweanlings, although effective in producing differences in openfield behavior, does not influence negative contrast. Since contrast, at least on the first postshift day, is thought to be at least partly due to the novelty of the postshift reward, as well as to emotionality (e.g., Capaldi, 1972; Flaherty, 1982), and preweaning handling has been reported to reduce neophobia in the consumption of sucrose solutions, as well as to reduce emotionality, the complete lack of an effect of handling on contrast was surprising. Experiments 2 and 3 were concerned with the effects of early handling on neophobia independent of the contrast procedure.

\section{Method}

Subjects

The subjects were 24 male albino rats obtained from seven litters (four $\mathrm{H}$ and three NH litters) bred in our laboratory from Sprague-Dawley males and females (multiparous) purchased from Charles River Breeding Laboratories. The animals were maintained on a 14-h/10-h light/dark cycle throughout the experiment.

\section{Apparatus}

The handling apparatus was the same as that used in Experiment 1. All subjects were tested in identical steel hanging cages measuring $24.5 \times 17.5 \times 18 \mathrm{~cm}$. The cages also served as the animals' home cages. Graduated cylinders containing the test solutions were attached to the front of the cages with springs during the testing periods.

\section{Procedure}

Breeding, handling, and maintenance procedures were the same as those used in Experiment 1.

Testing was begun when all animals were at least 65 days of age (range $=66-77$ days; mean age $=69.58$ days for the $\mathrm{H}$ animals and 71.67 days for the NH animals). The animals were maintained on food and water ad lib throughout the experiment (mean body weight $=433.75 \mathrm{~g}$ for the $\mathrm{H}$ animals and $456.08 \mathrm{~g}$ for the $\mathrm{NH}$ animals).

On the 2 test days, water bottles were removed and replaced with graduated cylinders containing either a $30 \%$ sucrose solution or a 3\% saline solution. The tubes were left in place for $30 \mathrm{~min}$ and then replaced with the water bottles. The order of solution presentation was counterbalanced so that one half of the $H$ animals and one half of the NH animals received the sucrose solution on Day 1. The remaining subjects received saline on Day 1 and sucrose on Day 2, forming four groups of 6 each defined by the factorial com- bination of order of presentation and handling condition. When possible, equal numbers of subjects from each litter were placed in each order condition.

The amount of solution consumed during the $30 \mathrm{~min}$ was recorded to the nearest milliliter. Testing took place between 11:30 a.m. and 12:30 p.m. on both days. The sucrose and saline solutions were prepared daily.

\section{Results}

The animals consumed more $30 \%$ sucrose solution than $3 \%$ saline solution $[F(1,20)=60.64, p<.01]$. The $H$ animals consumed more saline and sucrose than did the NH animals, but this difference was not reliable $[F(1,20)$ $=1.50, p>.05]$. The body weights of the $\mathrm{H}$ and $\mathrm{NH}$ animals at the beginning of testing did not differ [mean $=433.75 \mathrm{~g}$ for the $\mathrm{H}$ animals and $456.08 \mathrm{~g}$ for the $\mathrm{NH}$ animals; $t(22)=1.24, p<.05]$.

\section{Discussion}

The present experiment utilized the same strain of animals, the same duration and timing of the handling manipulation (Days 2-15), and the same daily time of testing as that used by Weinberg, Smotherman, and Levine (1978). However, there were several procedural differences that may be responsible for the failure to replicate the neophobia reduction in the $\mathbf{H}$ animals. Weinberg, Smotherman, and Levine used female animals and tested when they were between 90 and 122 days of age. The animals in the present experiment were tested between 66 and 77 days of age, and only male animals were used. The use of female animals may be a critical factor, since sex differences in response to sweet-tasting solutions in rats have been reported (Flaherty, Powell, \& Hamilton, 1979; Hamilton \& Timmons, 1976; Valenstein, Kakolewski, \& Cox, 1967; Wade \& Zucker, 1969). There have also been findings of sex differences in the response to novel stimuli (e.g., Russell, 1975), and Archer (1975) proposed that females may more readily approach novel stimuli as a result of hormonal influences during estrus. Furthermore, there have been reports of interactions between sex and handling treatments (e.g., Weinberg, Kahn, \& Levine, 1978). Therefore, it is possible that Weinberg, Smotherman, and Levine's results do not generalize to male rats.

\section{EXPERIMENT 3}

Experiment 2 failed to demonstrate any differences between $\mathrm{H}$ and NH animals in neophobia for novel solutions. Experiment 3 involved another attempt to assess such differences in a situation encountered by the shift animals in the contrast paradigm. That is, the animals were food-deprived and presented with a novel $4 \%$ sucrose solution in an environment other than the home cage.

\section{Method}

Subjects

The subjects were 24 male albino rats obtained from 13 litters (8 $\mathrm{H}$ and $5 \mathrm{NH}$ ) bred in our laboratory from Sprague-Dawley males 
and females (multiparous) purchased from Charles River Breeding Laboratories. The animals were maintained on a $14-\mathrm{h} / 10-\mathrm{h}$ light/dark cycle throughout the experiment.

\begin{abstract}
Apparatus
The handling apparatus was the same as that used in Experiments 1 and 2. Neophobia testing was conducted in two identical Plexiglas chambers measuring $30 \times 25 \times 25 \mathrm{~cm}$ enclosed in $99 \times 58$ $\times 109 \mathrm{~cm}$ sound-attenuating wooden enclosures. On one side of the chamber were two centrally located $1.5-\mathrm{cm}$-diam holes spaced $21.7 \mathrm{~cm}$ apart and $4 \mathrm{~cm}$ above the wire mesh floor. A graduated drinking tube, located outside the chamber, was programmed so that it could be moved into a drinking position in which the orifice of the drinking spout was centered in one of the $1.5-\mathrm{cm}$ holes, flush with the outside wall of the chamber. When the tube moved in, a pilot light mounted close to the access hole was illuminated. A contact relay circuit was used to measure the licking response. Latency to begin licking and number of licks per $5 \mathrm{~min}$ were recorded by relay programming equipment in the adjacent room. The equipment also controlled the insertion and withdrawal of the drinking tube.
\end{abstract}

\section{Procedure}

The breeding, handling, and postweaning care were identical to those in Experiments 1 and 2. Six days prior to neophobia testing, the animals were deprived to $80 \%$ of their free-feeding body weights (mean $80 \%$ body weight $=354.53 \mathrm{~g}$ for the $\mathrm{H}$ animals and $321.75 \mathrm{~g}$ for the NH animals) and were maintained at that level by limits on their daily food ration.

On the 2 days before testing began, each animal was placed in the test chamber for $15 \mathrm{~min}$ to allow for adaptation to the chamber. No sucrose solution was available at this time. One half of the $H$ animals and one half of the NH animals were run in each test chamber. On Test Days 1-4, the animals were placed into the test chambers. About $1 \mathrm{~min}$ later, the drinking tube containing a $4 \%$ sucrose solution was inserted for a $15-\mathrm{min}$ period. The latency to make the first lick, number of licks per $5 \mathrm{~min}$, and total amount consumed (in milliliters) were measured. The animals were then returned to their home cages. Thirty minutes later, they were given their daily food ration. The animals were weighed daily before placement in the carrying cage for transport to the test chamber. The 4\% sucrose solution was prepared, as in Experiment 1, every 2 days.

Because of the staggered births of the litters, the subjects were run at various times over a 60-day period. All animals were at least 70 days old at the beginning of testing (range $=70-95$ days of age; mean age $=78.5$ days for the $\mathrm{H}$ animals and 78.17 for the NH animals).

\section{Results and Discussion}

All latency scores were subjected to a $\log$ transformation prior to analysis.

There were no reliable differences between the $H$ and NH animals in number of licks $[F(1,22)<1.00]$, in milliliters of solution consumed $[F(1,22)<1.00]$, or in latency to initiate drinking $[F(1,22)<1.00]$. Both groups showed an increase in intake over days [licks, $F(3,66)=$ $10.72, p<.01$; milliliters consumed, $F(3,66)=24.16$, $p<.01]$ and a decrease in the latency to initiate drinking across days $[F(3,66)=6.38, p<.01]$.

The $\mathrm{H}$ and $\mathrm{NH}$ animals did not differ in body weight at the beginning of testing [mean $80 \%$ body weight of the $\mathrm{H}$ and $\mathrm{NH}$ animals $=354.42 \mathrm{~g}$ and $321.75 \mathrm{~g}$, respectively; $t(22)=1.53, p>.05$ ].
Thus, as in Experiment 2, there was no evidence of reduced flavor neophobia in handled animals. The fact that latency to initiate drinking declined across days and intake increased across days suggests that neophobia may have been present, but not differentially so in the $H$ and NH animals. Taken together, the results of Experiments 2 and 3 indicate quite strongly that the consumption of novel sucrose solutions is not influenced by early handling, at least in male rats.

\section{GENERAL DISCUSSION}

The effects of early handling on open-field behavior proved to be robust: Handled animals were substantially more active, entering more squares, spending more time in motion, and rearing more than nonhandled animals. In addition, there was a tendency for the handled animals to defecate less than the nonhandled animals. All of these results replicated those found in earlier experiments. However, there were no effects of the handling manipulation on sucrose intake in the three experiments: Degree of negative contrast was not influenced in Experiment 1, nor was latency to initiate consumption in the home cage (Experiment 2) or in a novel environment (Experiment 3). Amount of sucrose consumed was not influenced in any experiment. The results of these experiments suggest that early handling does not modify bait shyness and that the term neophobia, which is sometimes used in the description of the effects of early handling, should be used with caution.

The failure of early handling to modify negative contrast is inconsistent with interpretations of the two phenomena. Since the earliest observation of reward contrast, it has been interpreted in terms of emotional process (e.g., Crespi, 1942, 1944; Spence, 1956; Tinklepaugh, 1928). In the introduction to this paper, we reviewed evidence favoring this interpretation, evidence that included the ameliorating effects of anxiolytics on contrast; corticosterone elevation, which, under some conditions, accompanies negative contrast; the effects of amygdala lesions; and the effects of a disinhibitory stimulus on contrast. Yet the early handling manipulation is often interpreted as reducing emotionality. If this were true, one might expect that early handling would also reduce the degree of negative contrast.

The present paper is not alone in finding a failure of early handling to influence incentive contrast. Fagen and Rycek (1980) found that early handling did not modify simultaneous positive and negative contrast obtained in sucrose consumption, and Daly and Rosenberg (1973) found that early handling did not modify negative contrast obtained in a runway when rats were downshifted in food quantity. Since successive contrast in sucrose consumption, simultaneous contrast in sucrose consumption, and successive contrast in the runway are all somewhat different variants of contrast (Flaherty, 1982; Flaherty et al., 1977), it would seem to be a general finding that 
the processes involved in reward relativity are not influenced by preweaning handling.

The independence of contrast and open-field behavior is suggested not only by the differential effects of the preweaning manipulation on the two, but also by the correlational analysis of Experiment 1. This analysis showed a substantial degree of correlation among different measures of open-field behavior, but no correlation between open-field measures and sucrose-consumption measures obtained in the contrast phase of the experiment. Daly and Rosenberg (1973) found that early handling influenced the absolute level of running speed in the alleyway, but that, nevertheless, relative speeds between shifted and unshifted groups were not influenced by the handling manipulation. The fact that activity measures in both runway and open field are influenced by early handling, but contrast per se is not, is particularly interesting given that a contrast effect itself will produce increases in activity (Flaherty, Blitzer, \& Collier, 1978; Flaherty, Troncoso, \& Deschu, 1979).

Daly and Rosenberg (1973) suggested that early handling may influence fear-motivated behavior but have no effect on frustration-related behavior. This suggestion arose from the fact that rats handled early were less suppressed by punishment (response-contingent shock) than were nonhandled rats, but handling failed to influence contrast. However, the recent data reported by Sias and Brush (1984) suggest that even this limited generalization may be too broad. These authors reported that early handling did not influence avoidance responding in rats genetically selected to be either high or low avoiders. In their experiment, as in the present experiments, early handling did have the expected effects on open-field behavior.

In summary, the three experiments of this paper and the related experiments discussed here show that neonatal handling has a robust effect on open-field behavior and other measures of activity, but that this preweaning treatment does not influence negative contrast (measured in three different paradigms), the tendency of rats to consume novel foods in novel or familiar environments, or avoidance behavior in genetically selected rat strains. This pattern of results shows that early handling can have powerful effects on the behavior of adult rats, but it also shows that these effects may be limited in scope and that the psychological dimension influenced by the early handling treatment remains to be delimited.

\section{RETERENCES}

ABEL, E. L. (1971). Habituation as a factor in early handling. Joumal of Comparative \& Physiological Psychology, 74, 219-222.

ADER, R. (1970). The effect of early experience on the adrenocortical response to different magnitudes of stimulation. Physiology \& Behavior, 5, 837-859.

ARCHER, J. (1975). Rodent sex differences in emotional and related behavior. Behavioral Biology, 14, 451-479.

BECKRR, H. C. (1984). Effects of midazolam and three serotonin antagonists on consummatory negative contrast. Unpublished doctoral dissertation, Rutgers University, New Brunswick, NJ.
Becker, H. C., \& Flaherty, C. F. (1982). Influence of ethanol on contrast in consummatory behavior. Psychopharmacology, 77, 253-258.

Becker, H. C., \& Flaherty, C. F. (1983). Chlondiazepoxide and ethanol additively reduce gustatory negative contrast. Psychopharmacology, 80, 35-37.

Becker, H. C., Jarvis, M. F., Wagner, G. C., \&laherty, C. F. (1984). Medial and lateral amygdalectomy differentially influence consummatory negative contrast. Physiology \& Behavior, 33, 707-712.

CaPALDI, E. J. (1972). Successive negative contrast effect: Intertrial interval, type of shift, and four sources of generalization decrement. Journal of Experimental Psychology, 96, 433-438.

CAPALDI, E. J., \& LYNCH, D. (1967). Repeated shifts in reward magnitude: Evidence in favor of an associational and absolute (noncontextual) interpretation. Journal of Experimental Psychology, 75, 226-235.

COOPER, S. J., \& CRUmmY, Y. M. T. (1978). Enhanced choice of familiar food in a food preference test after chlordiazepoxide administration. Psychopharmacology, 59, 51-56.

Crespr, L. P. (1942). Quantitative variation in incentive and performance in the white rat. American Joumal of Psychology, 55, 467-517.

Crespi, L. P. (1944). Amount of reinforcement and level of performance. Psychological Review, 51, 341-357.

DALY, H. B. (1974). Arousal of frustration following gradual reductions in reward magnitude in rats. Journal of Comparative \& Physiological Psychology, 86, 1149-1155.

DAlY, H. B., Rosenberg, K. (1973). Infantile stimulation and its effects on frustration and fear-motivated behavior in rats. Leaming \& Motivation, 4, 381-396.

DENENBeng, V. H., GrotA, L. J. (1964). Social-seeking and noveltyseeking behavior as a function of differential rearing histories. Journal of Abnormal \& Social Psychology, 69, 453-456.

FAGEN, J. W., RYCEK, R. F. (1980). Effects of handling on positive and negative contrast effects. Developmertal Psychobiology, 13, 37-45.

FLAHERTY, C. F. (1982). Incentive contrast: A review of behavioral changes following shifts in reward. Animal Leaming \& Behavior, 10, 409-440.

Flaherty, C. F., Becker, H. C., \& Pohorecky, L. (1985). Correlation of corticosterone elevation and negative contrast varies as a function of postshift day. Animal Learning \& Behavior, 13, 309-314.

Flaherty, C. F., Bltrzer, R., Collier, G. H. (1978). Open-field behavior elicited by reward reduction. American Joumal of Psychology, 91, 429-443.

Flafierty, C. F., Caproo, M. (1976). The dissociation of instrumental and consummatory measures of contrast. American Journal of Psy chology, 89, 485-498.

Flaherty, C. F., Lombard, B. R., KaPUST, J., \& D'Amato, M. R. (1977). Incentive contrast undiminished by extended testing, imipramine, or chlordiazepoxide. Pharmacology, Biochemistry, \& Behavior, 7, 315-322.

Flahterty, C. F., Lombard, B. R., Wrightson, J., * Deptula, D. (1980). Conditions under which chlordiazepoxide influences gustatory contrast. Psychopharmacology, 67, 269-277.

Flaherty, C. F., Powell, G., Hamlton, L. W. (1979). Septal lesion, sex, and incentive shift effects on open-field behavior of rats. Physiology \& Behavior, 22, 903-909.

Flaherty, C. F., \& Sepanak, S. J. (1978). Bidirectional contrast, matching, and power functions obtained in sucrose consumption by rats. Animal Leaming \& Behavior, 6, 313-319.

Flaherty, C. F., Troncoso, B., Deschu, N. (1979). Open-field behavior, correlated with reward availability and reward shift in three rat strains. American Joumal of Psychology, 92, 385-400.

Halturyer, G. C., Denenbeng, V. H., a ZnRkow, M. X. (1967). Modification of plasma corticosterone response as a function of infantile stimulation and electric shock parameters. Physiology \& Behavior, 2, 61-63.

Hamitron, L. W., * Tmmons, C. K. (1976). Sex differences in response to taste and postingestive consequences of sugar intake. Physiology \& Behavior, 17, 221-225.

Hess, J. L., Denenberg, V. H., Zarrow, M. X., \& Pfeifer, W. D. 
(1969). Modification of the corticosterone response curves as a function of handling in infancy. Physiology \& Behavior, 4, 109-111.

IVINSKIs, A. (1966). A note on the open-field test of emotionality. Australian Joumal of Psychology, 18, 276-280.

Ivinskus, A. (1968). The reliability of behavioral measures obtained in the open field. Australian Jowrnal of Psychology, 20, 173-177.

LEVINE, S. (1956). A further study of infantile handling and adult avoidance learning. Journal of Personality, 25, 70-80.

Levine, S., Haltmityer, G. C., Karas, G., De Denenberg, V. H. (1967). Physiological and behavioral effects of infantile stimulation. Physiology \& Behavior, 2, 55-59.

Price, E. O., * Huck, U. W. (1976). Open-field behavior of wild and domestic Norway rats. Animal Learning \& Behavior, 4, 125-130.

RAY, O., Hockruuser, S. (1969). Growth hormone and environmental complexity effects on behavior in the rat. Developmental Psychobiology, 1, 311-317.

Russell, P. A. (1975). Sex differences in rats' response to novelty measured by activity and preference. Quarterly Journal of Experimental Psychology, 27, 585-589.

Sus, P. E., BRUSH, F. R. (1984, November). Genetic differences in avoidance leaming: Effects of early handling. Paper presented at the meeting of the Psychonomic Society, San Antonio.

SPENCE, K. W. (1956). Behavior theory and conditioning. New Haven: Yale University Press.
TinkLepaugh, O. (1928). An experimental study of representative factors in monkeys. Joumal of Comparative Psychology, 8, 197-236.

Valenstein, E. S., Kakolewset, J. W., \& Cox, V. C. (1967). Sex differences in taste preference for glucose and saccharin solutions. Science, 156, 942-943.

WADE, G. N., ZUCKRR, I. (1969). Taste preferences of female rats: Modification by neonatal hormones, food deprivation, and prior experience. Physiology \& Behavior, 4, 935-943.

Walsh, R. N., Cummins, R. A. (1976). The open-field test: A critical review. Psychological Bulletin, 83, 482-504.

WeINBerg, J., Kakn, E. A., \& Levine, S. (1978). Differential effects of handling on exploration in male and female rats. Developmental Psychobiology, 11, 251-259.

Weinberg, J., Smotherman, W. P., \& LeVINe, S. (1978). Early handling effects on neophobia and conditioned taste aversion. Physiology \& Behavior, 20, 589-596.

Whimasey, A. E., Denenkerg, V. H. (1967). The two independent behavioral dimensions in open-field performance. Journal of Comparative \& Physiological Psychology, 63, 500-504.

(Manuscript received May 27, 1986; revision accepted for publication October 29, 1986.) 